\title{
Intrathoracic gastric volvulus: an autopsy case report
}

\author{
Cristiane Rúbia Ferreira ${ }^{a}$, Linda Ferreira Maximiano ${ }^{b}$, \\ Victor Manuel Lobo dos Santos ${ }^{b}$, João Augusto dos Santos Martines ${ }^{c}$
}

Ferreira CR, Maximiano LF, Santos VML, Martines JAS. Intrathoracic gastric volvulus: an autopsy case report. Autopsy Case Rep [Internet]. 2013;3(2):21-29. http://dx.doi.org/10.4322/acr.2013.014

\section{ABSTRACT}

First described by Berti in 1866, gastric volvulus (GV) is an uncommon and potentially lethal entity. GV occurs when the stomach twists by more than $180^{\circ}$ resulting in obstruction of the alimentary tract, visceral ischemia, necrosis, and perforation. It is classified according to the rotation axis in organoaxial, mesenteroaxial or a combination of both. The clinical presentation can be acute, and is usually severe or chronic, which sometimes may be asymptomatic. It predominantly occurs in the fifth decade of life, but children, mainly those under the age of 1 year, may be affected. No ethnicity or gender was observed to show predominance. This entity is related to gastric, diaphragmatic disorders as well as laxity of gastric ligaments. Acute GV may complicate with incarceration and strangulation of the stomach when gastric necrosis ensues. These cases show a mortality rate of $60 \%$. The authors report the fatal case of a surgically treated GV in a 43-year-old female patient who looked for medical care only after 1 month of initial symptoms. Diagnosis was confirmed with a thoracic and abdominal axial computed tomography. Besides the entire stomach being herniated and twisted into the thoracic cavity, the pancreas was pulled up through the hiatal orifice, provoking acute pancreatitis. Because of gastric necrosis and perforation, gastroenteric fluid drained into the mediastinum and left pleural space. The postoperative outcome was unfavorable resulting in the patient's death. The authors call attention to the severeness of the disease, and therefore the need of precocity of diagnosis and surgical treatment.

Keywords: Stomach Volvulus; Abdominal Pain; Mediastinitis; Pancreatitis; Shock, Septic.

\section{CASE REPORT}

A 43-year-old woman sought medical attention complaining of abdominal and lumbar pain radiating to the back, accompanied by nausea and eventually nonproductive retching. She denied fever. She had been presenting these symptoms over the past month, which progressively worsened without relief from over-the-counter painkillers.
Her past medical history included two cesarean sections, cholecystectomy and hiatoplasty for hiatal hernia-the latter 6 years ago.

On physical examination the patient presented an ill-looking appearance and a pained expression. She was pale, anicteric, afebrile. The

\footnotetext{
a Anatomic Pathology Service - Hospital Universitário - Universidade de São Paulo, São Paulo/SP - Brazil.

${ }^{\text {b }}$ Department of Surgery - Hospital Universitário - Universidade de São Paulo, São Paulo/SP - Brazil.

${ }^{c}$ Diagnostic Imaging Service - Hospital Universitário - Universidade de São Paulo, São Paulo/SP - Brazil.
}

Copyright $\odot 2013$ Autopsy and Case Reports - This is an Open Access article distributed of terms of the Creative Commons Attribution NonCommercial License (http://creativecommons.org/licenses/by/3.0/) which permits unrestricted non-commercial use, distribution, and reproduction in any médium provided article is properly cited. 
respiratory pattern was normal. Blood pressure was 124/82 $\mathrm{mmHg}$; pulse was 84 regular beats per minute; respiratory rate was 20 respiratory movements per minute; and room air oximetry was $98 \%$. Cardiac and pulmonary examination was normal except for the presence of thoracic kyphosis. The abdominal palpation was thoroughly painful; the rebound tenderness test was negative; and bowel sounds were present and normal. The laboratory work up is shown in Table 1.

The patient underwent an abdominal computed tomography, which resulted in gastric volvulus (GV) herniated into the thoracic cavity (Figures 1 and 2), organoaxial and mesenteroaxial. The splenic arteriovenous vascular pedicle and the pancreatic tail were pulled up through the diaphragmatic esophageal orifice (Figure 3 ).

In the hours after admission, the patient presented tachypneia, decreased oxygen saturation, and hypotension. She underwent an urgent exploratory laparotomy. Among the surgical findings were: a) herniation of the stomach into the chest, which was twisted on its own axis (volvulus) with necrosis and perforation af the greater curvature; b) the presence of a huge amount of gastro enteric contents in the left pleural cavity. Reduction of the stomach to the abdominal cavity, vertical gastrectomy, and thoracic and mediastinal drainage were performed.

The patient was referred to the intensive care unit where she remained sedated, under mechanical ventilatory support, depending on continuous infusion of norepinephrine in an effort to attain hemodynamic stabilization. Multiple organ failure ensued and the patient died on the second postoperative day.

\section{Autopsy Findings}

At the opening of the thoracic and abdominal cavities, there was small amount of foul-smelling enteric liquid within the pleural cavity, with areas of

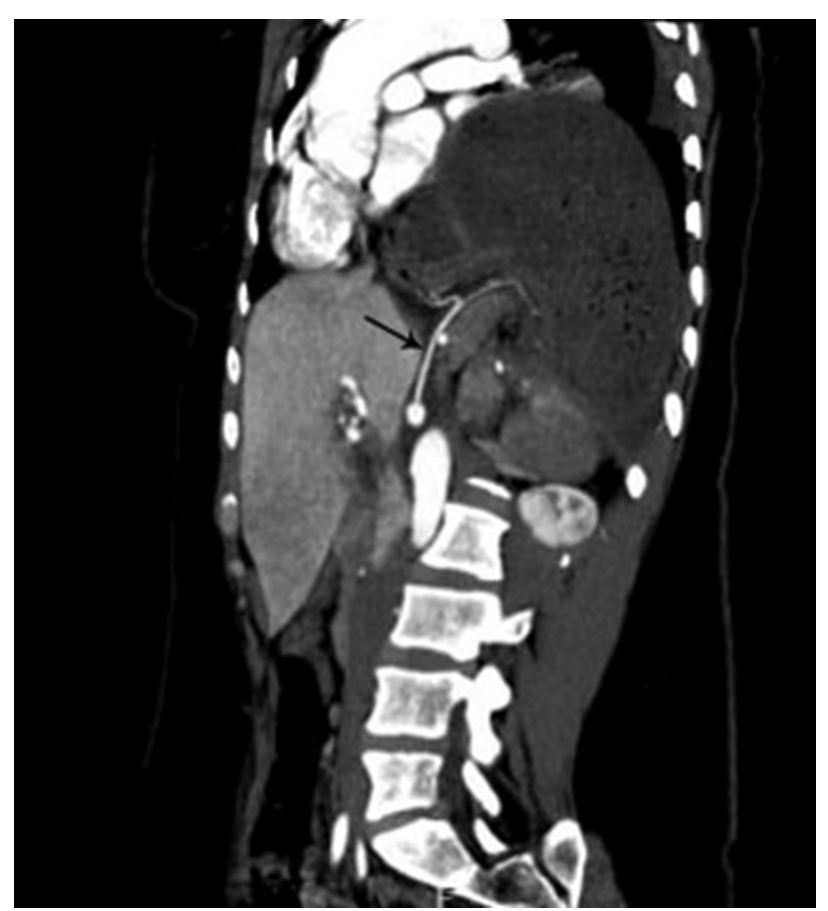

Figure 1 - Computed tomography (CT) of the thorax/abdomen, sagittal reconstruction showing the intrathoracic stomach and stretching of the left gastric artery (arrow).

Table 1 - Admission laboratory workup

\begin{tabular}{cccccc}
\hline & \multicolumn{2}{c}{ RV } & & \\
\hline Hemoglobin & 15.8 & $12.3-15.3 \mathrm{~g} \%$ & Creatinine & 1.09 & $0.4-1.3 \mathrm{mg} / \mathrm{dL}$ \\
Hematocrit & 48.9 & $36.0-45.0 \%$ & Potassium & 3.8 & $3.5-5.0 \mathrm{mEq} / \mathrm{L}$ \\
Leucocytes & 18.4 & $4.4-11.3 \times 103 / \mathrm{mm}^{3}$ & Sodium & 140 & $136-146 \mathrm{mEq} / \mathrm{L}$ \\
Bands & 0 & $1-5 \%$ & ALT & 20 & $9-36 \mathrm{U} / \mathrm{L}$ \\
Segmented & 84 & $45-70 \%$ & AST & 35 & $10-31 \mathrm{U} / \mathrm{L}$ \\
Eosinophil & 0 & $1-4 \%$ & Total bilirubin & 0.5 & $0.3-1.2 \mathrm{mg} / \mathrm{dL}$ \\
Basophil & 0 & $0-2.5 \%$ & Amylase & 859 & $70-140 \mathrm{mg} / \mathrm{dL}$ \\
Lymphocyte & 9 & $18-40 \%$ & Lipase & 1038 & $20-104 \mathrm{U} / \mathrm{L}$ \\
Monocyte & 7 & $2-9 \%$ & Cai+ & 1.06 & $1.15-1.35 \mathrm{mmol} / \mathrm{L}$ \\
Platelets & $265.10^{3}$ & $150-400 \times 103 / \mathrm{mm}^{3}$ & PT (INR) & 1.59 & 1 \\
CRP & 180 & $<5 \mathrm{mg} / \mathrm{L}$ & &
\end{tabular}

ALT = alanine aminotransferase; $\mathrm{AST}=$ aspartate aminotransferase; $\mathrm{BUN}$ = blood urea nitrogen; Cai+ = ionized calcium; CRP = C-reactive protein; INR = international normalized ratio; PT = prothrombin time; RV = reference value. 


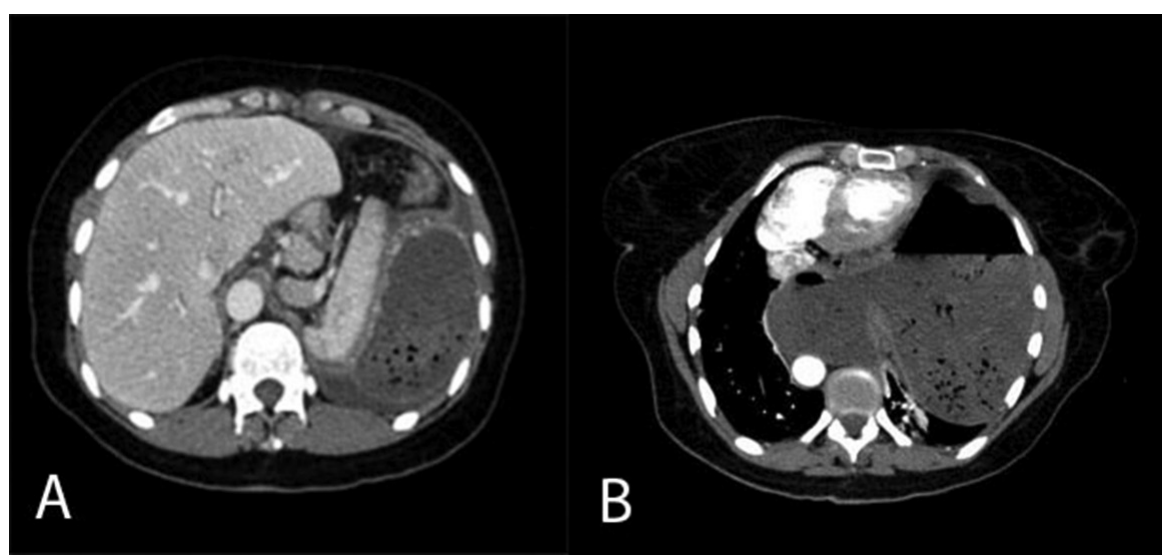

Figure 2 - A and B - Axial CT of the thorax/abdomen showing the dilated intrathoracic stomach. In A, note the presence of pleural effusion surrounding the herniated viscera.

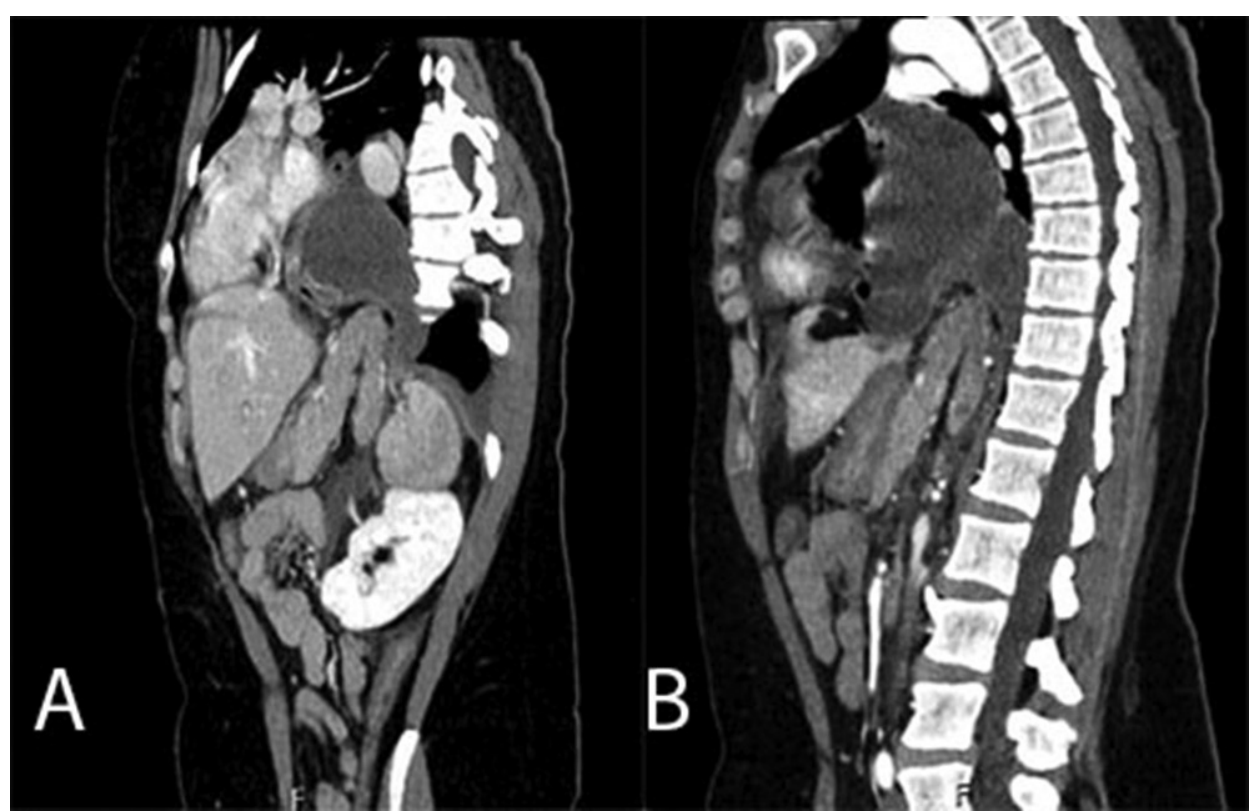

Figure 3 - A and B - CT of thorax/abdomen - sagittal reconstruction - showing an enlargement of the esophageal hiatus with kinking of the body/tail of the pancreas hinting to the chest. (An oblique view in A).

thick brownish fibrinous material deposited on the pericardial and left pleural surface (Figure 4A and 4B). The right lung weighed $403 \mathrm{~g}$ (reference value [RV]: $403 \mathrm{~g}$ ) and the left lung weighed $518 \mathrm{~g}$ (RV: 375); both, but mainly the left, showed a wine-colored cut surface (Figure 4C and 4D). On microscopy, there were areas of congestion, edema, alveolar hemorrhage, pneumonia, areas of diffuse alveolar damage, and focal thrombosis with infarction of the subpleural parenchyma. There was also acute pleurisy with focal food debris (Figures $5 A-5 C$ ).

The heart weight $279 \mathrm{~g}$ (RV: $262 \mathrm{~g}$ ) and showed petechiae on the anterior pericardial surface. On microscopy, there were foci of chronic myocarditis in the subendocardium (Figures $6 \mathrm{~A}$ and $6 B)$.
In the posterior mediastinum, the diaphragm showed a solution of continuity (laceration) through which a portion of the stomach crept (Figure 4B). After the longitudinal opening of the esophagus and stomach, a suture was identified in the gastric wall (Figure 7). On microscopy, there was serositis on the gastric serosae surface (Figure 7).

The remaining organs showed alterations related to septic shock, such as acute pancreatitis with steatonecrosis (pancreas weighed $129 \mathrm{~g}$; RV: $110 \mathrm{~g}$ ); hepatic congestion with foci of lobular necrosis predominantly in zone 3 , and microvesicular steatosis (liver weighed $1467 \mathrm{~g}$; RV range: $1760-2320 \mathrm{~g}$ ); acute tubular necrosis (both kidneys weighed $177 \mathrm{~g}$; RV: $288 \mathrm{~g}$ ) (Figure 8); and foci of recent mucosal and submucosal hemorrhage in small and large intestines. 


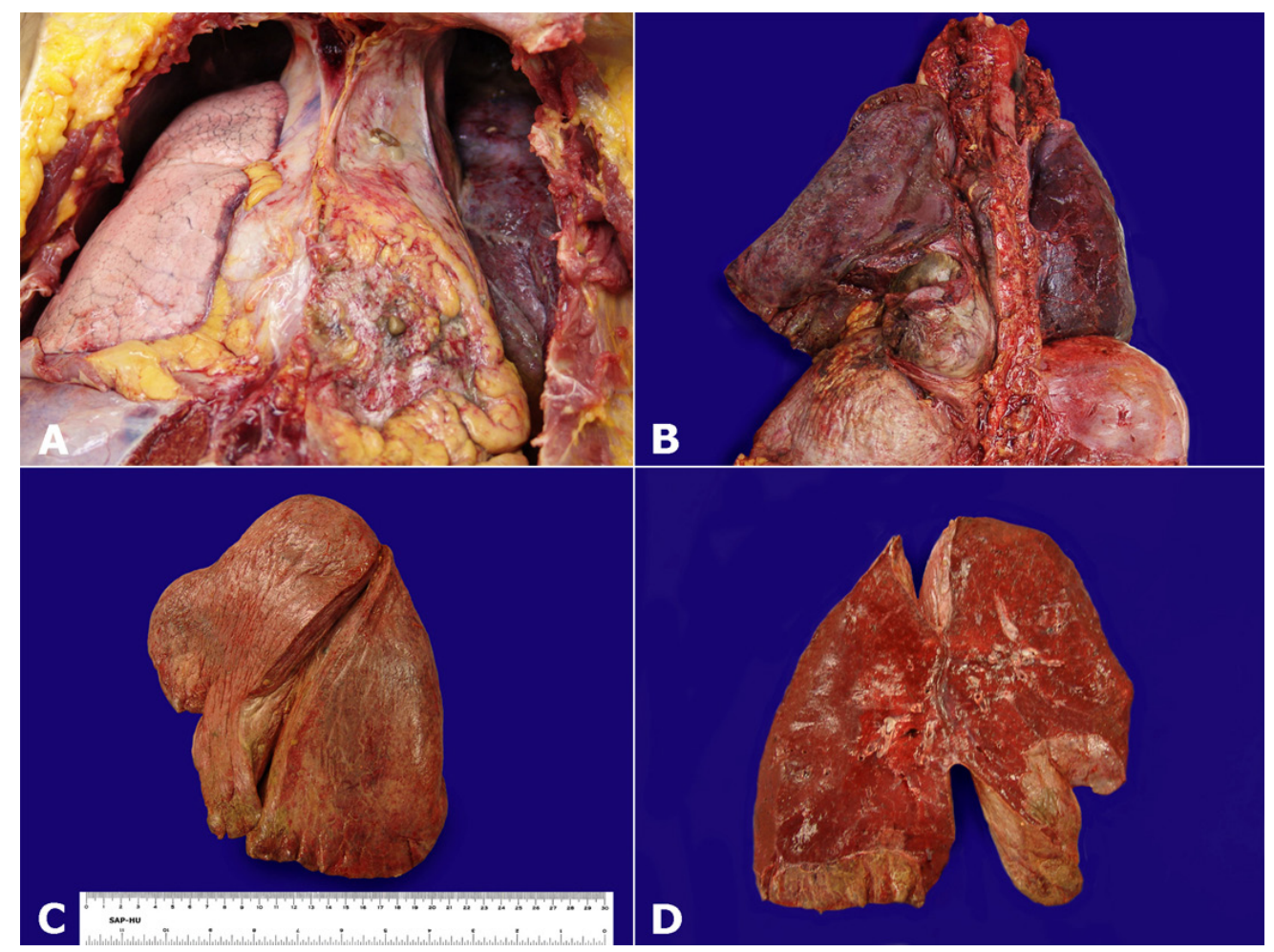

Figure 4-A - Gross appearance of the thoracic cavity. Observe the deposition of brownish fibrinous material on the collapsed left lung and on the pericardial sac; B - Gross appearance of the posterior mediastinum showing mediastinitis Note the deposition of fibrinous material on the surface of the lungs and a protrusion of the diaphragm wall into de thoracic cavity; C - Gross appearance of left lung showing wine-colored and rough pleural surface; D - Gross appearance of the left lung, which showed the wine-colored cut surface.

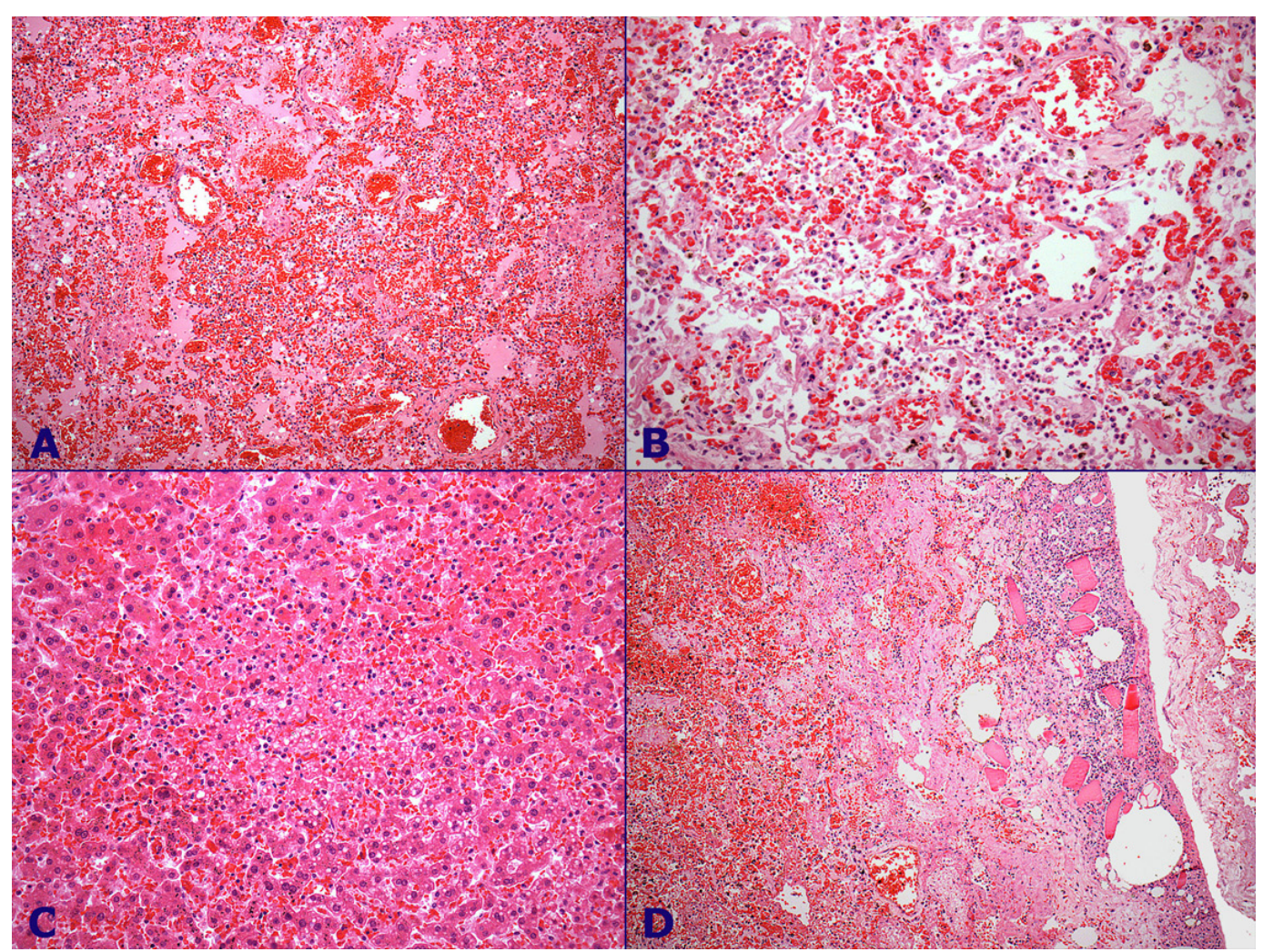

Figure 5 - Photomicrography of the lung - A (HE - 100X) and B (HE - 200X)- capillary congestion of the pulmonary parenchyma. Note edema, hemorrhage, foci of fibrinous material deposition and acute neutrophilic infiltration within the alveolar spaces, featuring areas of pneumonia and diffuse alveolar damage; C $(\mathrm{HE}-100 \mathrm{X})$ - Area of infarction of the subpleural pulmonary parenchyma; D (HE - 100X) - Pleural surface with acute inflammatory infiltrate and focal food debris. 

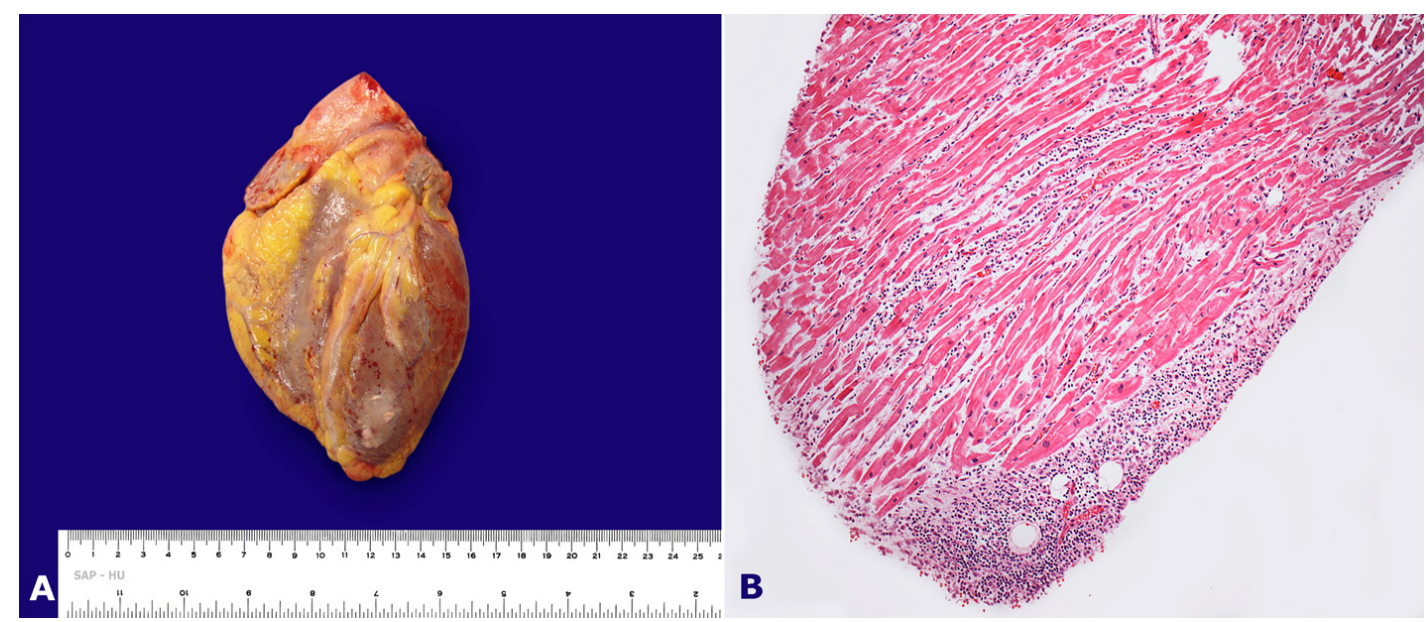

Figure 6 - A - Gross view of the heart showing petechiae on the anterior pericardial surface; B - Photomicrography of the heart showing lymphocytic inflammatory infiltrate amid the cardiomyocytes and at the subendocardium layer.

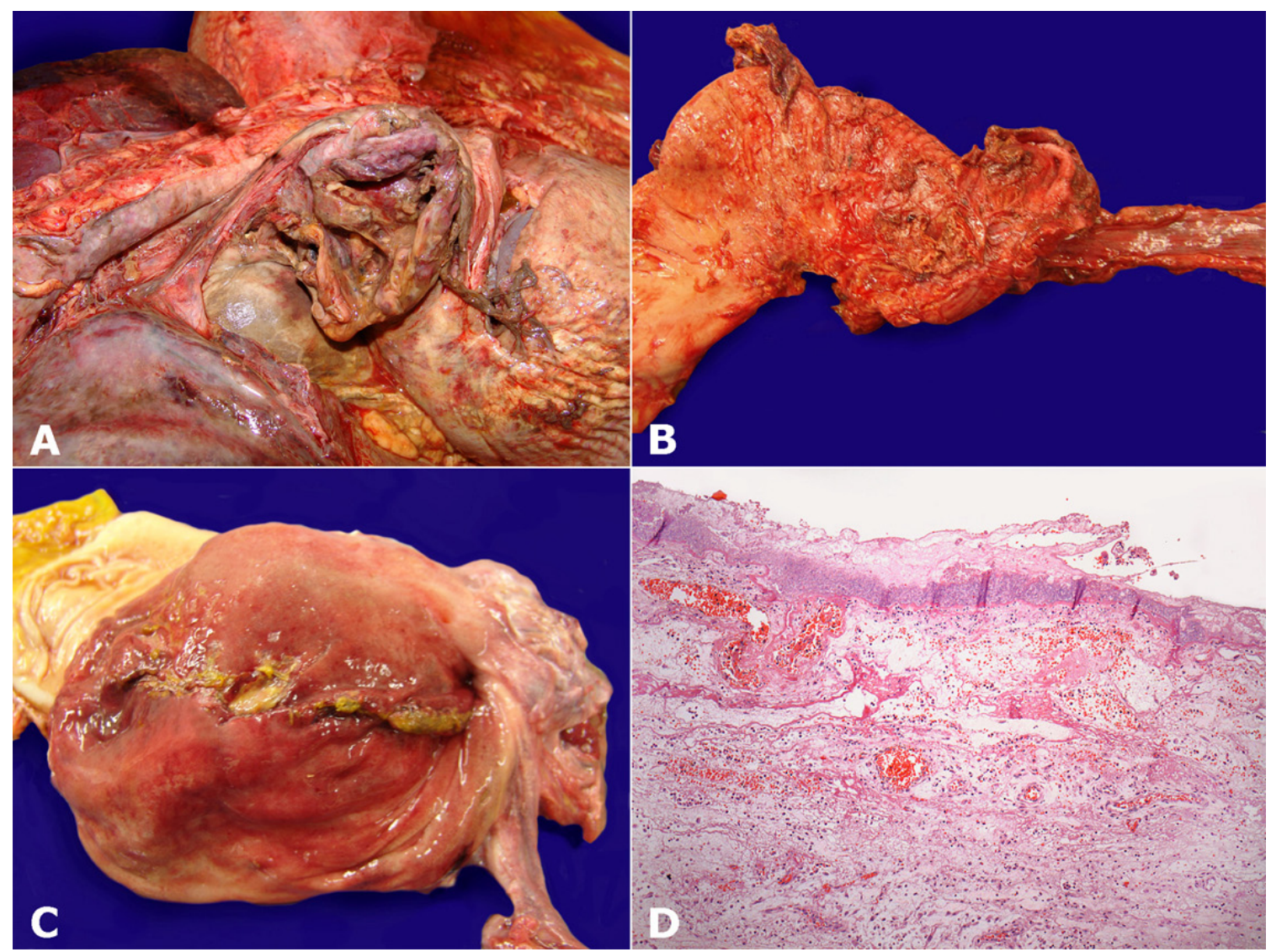

Figure 7 - A - Gross view of the diaphragm wall protrusion with a solution of continuity (laceration) through which a portion of the stomach crept into; B - Gross appearance of the suture on the gastric wall; C - Gross appearance of the gastric mucosa suture; $\mathbf{D}(\mathrm{HE}-100 \mathrm{X})$ - Photomicrography of the gastric serosae with an acute inflammatory infiltrate.

\section{DISCUSSION}

GV is a rare and potentially lethal condition, defined as an acquired rotation of the stomach or part of the stomach by more than $180^{\circ}$ creating a closed-loop obstruction. ${ }^{1}$ It was first described in 1866 by Berti based on the autopsy of a 61 -year-old woman. ${ }^{2,3}$ Gastric volvulus is conventionally thought of as an intra-abdominal condition, but the uncommon intrathoracic variant is also observed. Intrathoracic GV is considered a surgical emergency due to the risk of visceral ischemic necrosis, perforation, and serious cardiorespiratory impairment. ${ }^{4-6}$

The incidence of GV predominates the fifth decade of life, although $10-20 \%$ of the cases 


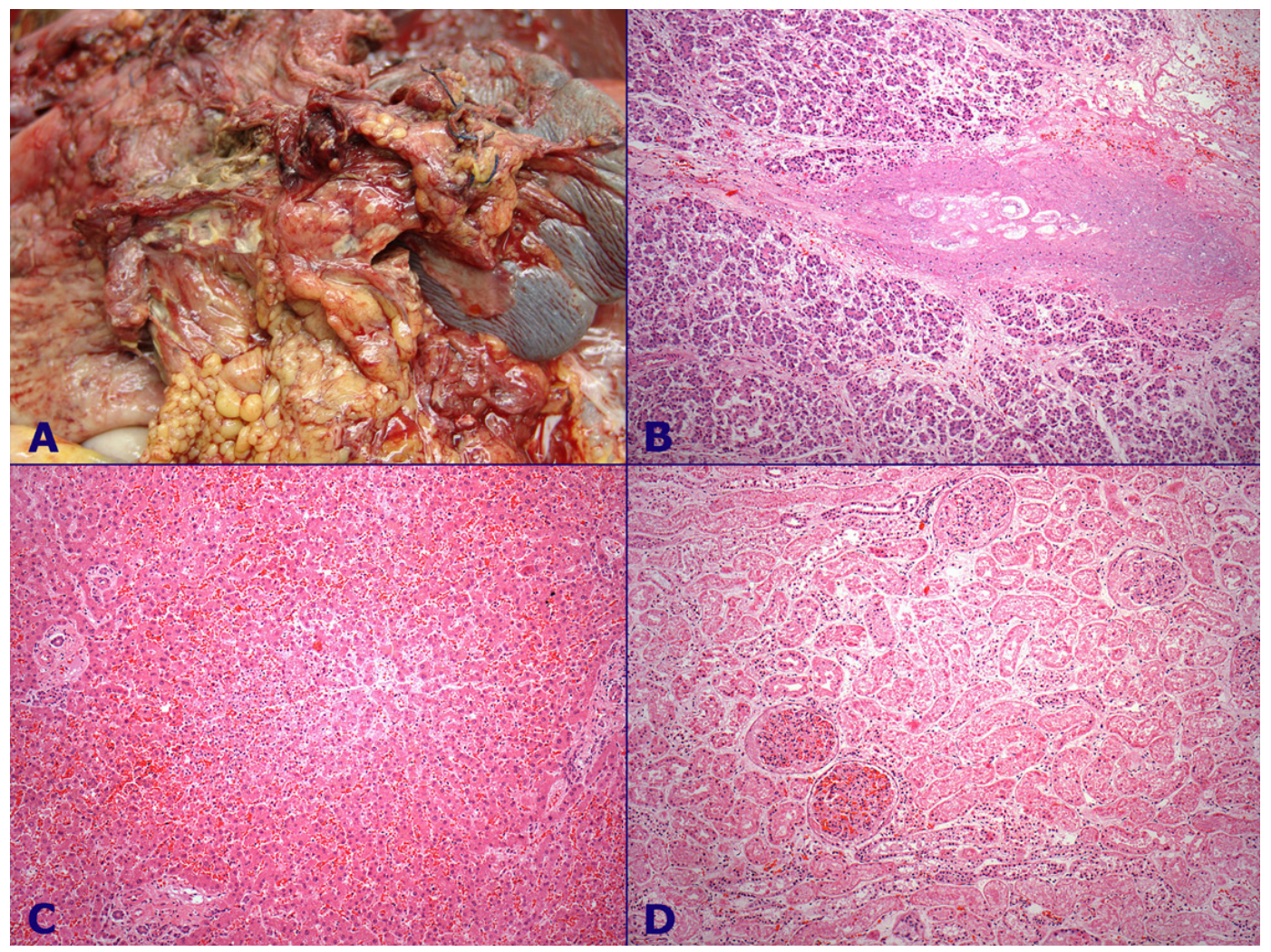

Figure 8 - A - Gross appearance of body and tail of the pancreas with foci of steatonecrosis; B - Photomicrography of the pancreas (HE - 100X) showing a focus of steatonecrosis as well as acute inflammatory infiltrate; C - Photomicrography of the liver (HE - 100X) showing hepatic congestion with lobular necrosis in zone 3; D - Photomicrography of the kidney (HE - 100X) showing acute tubular necrosis.

occur among children under 1 year of age. Gender or ethnicity do not show any predominance. ${ }^{3} \mathrm{GV}$ can be classified according to its site, etiology, axis of rotation, and whether it presents acutely or chronically. ${ }^{3}$

According to Kanai's ${ }^{7}$ classification, the causes of GV can be categorized as idiopathic and secondary. The idiopathic type includes looseness of the gastric ligaments, gastroptosis, active gastric peristalsis, and colonic distension. The stomach is anchored at the cardia and tethered by the gastrocolic, gastrohepatic, gastrophrenic, and gastrosplenic ligaments. Despite this attachment, it has a relative mobility so that some dislocation may be normal while storing, grinding, and mixing food. Intermittent episodes of asymptomatic gastric rotation do occur, ${ }^{8}$ but never more than $180^{\circ}$, unless the gastrosplenic or gastrocolic ligaments are divided. Thus, if the gastric ligaments are lax any cause of gastric distention can trigger excessive rotation, setting the stage for volvulus. ${ }^{8,9}$ The secondary type, which is more common, includes gastric and diaphragmatic disorders, such as gastric ulcer and gastric tumor, diaphragmatic hernia, and muscle laxity. ${ }^{7,8}$ The diaphragmatic disorders represent $43 \%$ of the underlying causes of GV.
Singleton ${ }^{10}$ proposed a classification according to the axis of rotation. The organoaxial is the most common (59-60\%), being characterized by a gastric rotation around an axis that connects the gastroesophageal junction and the pylorus. The antrum rotates in the opposite direction to the fundus of the stomach, so that the greater curvature of the stomach rests above the lesser curvature. In this particular type, the stomach lies horizontally on plain abdominal radiography.,11 Obstruction can occur at the gastroesophageal junction, the pylorus, or both, and strangulation is more likely to occur. This particular type is associated with paraesophageal hernias and diaphragmatic eventration. ${ }^{8}$ The second type is the mesenteroaxial rotation $(29 \%)$ that is characterized by rotation of the stomach along an axis perpendicular to its longitudinal axis (transgastric axis). In this type, the antrum rotates anteriorly and superiorly so that the posterior surface of the stomach lies anteriorly. The stomach lies in the vertical plane with the antrum and pylorus rotated anterior and superior to the gastroesophageal junction. ${ }^{3}$ This rotation is usually incomplete and occurs intermittently. In this type, gastrosplenic ligament laxity is thought to be the predisposing factor. ${ }^{8}$ Most cases of chronic GV are related to this mesenteroaxial rotation. The third 
and rarest form of $\mathrm{GV}$ is when the stomach twists organoaxially and mesenteroaxially, resulting in a combined volvulus $(12 \%) .3$

GV can present as an acute surgical emergency or a chronic recurring entity. Acute GV presents as severe left upper quadrant or left lower thoracic pain, which may radiate to the back, neck, or interscapular area. Other symptoms may also be dyspnea, vomiting, and dry heaves. The most common complications of acute GV are incarceration, strangulation, and perforation. Patients suffering a gastric infarction may present with gastrointestinal hemorrhage, cardiopulmonary failure, or shock. The mortality rate ranges between $30 \%$ and $50 \%$ for acute GV and this rate increases to $60 \%$ if strangulation and infarction occur. ${ }^{8,12}$

Chronic GV may be asymptomatic, reported as an incidental finding on routine chest plain x-ray or serial contrasted gastrointestinal radiography, or it may present with vague symptoms, such as uncharacteristic upper abdominal pain, dysphagia, early satiety, bloating, shortness of breath, or belching. It also may be misinterpreted as peptic ulcer disease or cholecystitis. ${ }^{8,12}$

GV is seldom initially considered when a patient complains of abdominal or chest pain associated with nausea and vomiting. In cases of acute GV, the classical Borchardt's triad is present in $70 \%$ of the cases. This triad, described in 1904, comprehends retching without vomiting, severe epigastric pain, and an inability to pass a nasogastric tube. ${ }^{3,8,13}$

Additional findings were reported by Carter et al., ${ }^{14}$ including few abdominal findings when the stomach is completely intrathoracic; a gasfilled viscus in the lower chest or upper abdomen shown on chest x-ray; and obstruction at the site of volvulus shown by upper contrasted serial study. ${ }^{8}$

In the case reported here, the patient presented classical symptoms of acute GV, but the differential diagnosis with incarcerated paraesophageal hernia $(\mathrm{PH})$ was challenging, considering her past medical history of hiatoplasty for hiatal hernia $(\mathrm{HH})$. Abdominal CT suggested a combined type of GV.

$\mathrm{HH}$ is defined as a protrusion of the abdominal contents, usually the stomach, into the thorax through the esophageal hiatus. $\mathrm{HH}$ is classified into four variants: type I, sliding hernia, is the most common; type II, rolling hernia, where the gastroesophageal junction is anchored in the regular subdiaphragmatic position with herniation of part or the whole stomach, which lies alongside the esophagus in the thorax; type III hernia is represented by a mix of type I and type II; and type IV hernia, involves other abdominal viscera in addition to the stomach in the herniation process. Types II-IV are collectively $\mathrm{PH}$, which represents a small proportion of all $\mathrm{HH}$. They can lead to severe complications like incarceration, volvulus, or strangulation. ${ }^{15,16}$

Differential diagnosis between $\mathrm{GV}$ and $\mathrm{PH}$ may be a tough task. Both entities rarely feature on the list of diagnoses of acute chest or epigastric pain. A plain chest radiograph may exhibit a retrocardiac air fluid level, but cannot reliably differentiate all varieties of hernias. ${ }^{15}$ Organoaxial volvulus is difficult to image, particularly if no diaphragmatic defect is present. Plain films show a horizontally oriented stomach with a single air fluid level and a paucity of distal gas. ${ }^{8}$ On supine radiographs of the mesenteroaxial volvulus, the stomach appears spherical. Upright films often show a double air fluid level; occasionally the inferior air-fluid is located in a normal position beneath the diaphragm while the upper one (herniated antrum) lies in the retrocardiac mediastinum. ${ }^{8}$ An upper gastrointestinal contrasted serial study is considered a highly sensitive and specific radiological exam. ${ }^{17}$ Barium contrast studies can demonstrate the position of the gastroesophageal junction, esophageal shortening, and esophageal dysmotility. ${ }^{15}$ Organoaxial volvulus may show a low lying gastroesophageal junction and a horizontal or inverted stomach with the cardia and pylorus at the same level. ${ }^{8}$

However, patients presenting acute abdomen frequently undergo a CT scan. The use of abdominal $\mathrm{CT}$ in these cases, especially in GV, can lead to the immediate diagnosis with all the anatomical details, and offer extra-luminal information, such as the presence of life-threatening visceral ischemia, placing the CT scan in a position of undoubted advantage over other imaging methods for this diagnosis. ${ }^{17-19}$

Upper gastrointestinal endoscopy can also accurately diagnose and classify $\mathrm{HH}$, and may allow assessment of organoaxial rotation on GV. This diagnostic method is generally performed in order to differentiate other causes of upper gastrointestinal complaints, including malignancy. ${ }^{15}$ 
Treatment of GV and PH may be conservative or surgical. Conservative management consists of endoscopic reduction or percutaneous endoscopic gastrostomy, both of which are less invasive, especially for high-risk patients..$^{3,4,20,21}$ Surgical intervention is the treatment of choice in acute cases when incarceration or strangulation are present. Surgery aims to reduce symptoms of dysphagia, reflux, epigastric and chest pain, and improve cardiovascular function. ${ }^{15}$ Even though there are no randomized controlled trials or prospective studies comparing laparoscopic repair versus open surgery, the literature shows that laparoscopic surgery results in lower blood loss, decreases intraoperative complications, reduces the overall morbidity, and shortens the hospital stay. ${ }^{5,15}$ Surgical intervention involves gastric decompression, reduction of the $\mathrm{GV}$ or $\mathrm{PH}$, correction of predisposing factors, closure the hernial orifice, and anchorage of the stomach to prevent recurrence. ${ }^{1,8,15}$ The preferred surgical procedure is anterior gastropexy, in which the greater curvature of the stomach is anchored to the anterior abdominal wall, but if gastric necrosis has occurred, partial or total gastrectomy may be required depending on the extent of ischemic injury. 8,15

In the case reported here, the outcome was adverse. Despite the reported high occurrence of death among patients with complicated GV, we infer that the outcome of this patient could have been different. She was symptomatic for a long time, but only looked for medical attention at an advanced stage, when severe complications were already set up. Once in the medical facility, the diagnosis was easily and promptly established, but the stomach presented ischemic suffering, and rupture to the pleural space and mediastinitis ensued. Empyema, mediastinitis and surgical trauma contributed to septic shock and death.

\section{REFERENCES}

1. Wasselle JA, Norman J. Acute gastric volvulus: pathogenesis, diagnosis, and treatment. Am J Gastroenterol. 1993;88:17804. PMid:8213725.

2. Berti A. Singolare attortigliamento dell'esofago col duodeno sequito da rapida morte. Gazz Med Ital .1866;9:139-41. Italian

3. Rashid F, Thangarajah T, Mulvey D, et al. A review article on gastric volvulus: A challenge to diagnosis and manangement.
Int J Surg. 2010;8:18-24. PMid:19900595. http://dx.doi. org/10.1016/j.ijsu.2009.11.002

4. Matsumoto N, Oki E, Morita M, et al. Successful treatment of acute esophageal necrosis caused by intrathoracic gastric volvulus: report of a case. Surg Today. 2009;39:1068-72. PMid:19997803. http://dx.doi.org/10.1007/s00595-008-3983-4

5. Yano F, Stadlhuber J, Tsuboi K, et al. Outcomes of surgical treatment of intrathoracic stomach. Dis Esoph. 2009;22:2848. PMid:19207556. http://dx.doi.org/10.1111/j.14422050.2008.00919.x

6. Kim HH, Park SJ, Park MI, Moon W. Acute intrathoracic gastric volvulus due to diaphragmatic hernia: a rare emergency easily overlooked. Case Rep Gastroenterol. 2011;5:272-7. PMid:21887128 PMCid:3153339. http://dx.doi. org/10.1159/000328444

7. Kanai T. About gastric volvulus. Stomach Intestine. 1969;4:731-42. PMid:17659139.

8. Sevcik WE, Steiner IP. Acute gastric volvulus: case report and review of the literature. CJEM.1999;1:200-3.

9. Dalgaard JB. Volvulus of the stomach. Acta Clin Scand. 1952;103:131-6.

10. Singleton AC. Chronic gastric volvulus. Radiology. 1940;34:53-61. http://dx.doi.org/10.1016/S08997071(02)00549-1

11. Shivanand G, Seema S, Srivastava DN, et al. Gastric volvulus: acute and chronic presentation. Clin Imaging. 2003;27:265-8. http://dx.doi.org/10.1002/bjs.1800771219

12. Haas $O$, Rat $P$. Surgical results of intrathoracic gastric volvulus complicating hiatal hernia. Br J Surg. 1990;77:1379-81.

13. Borchardt M. Zun pathologie and therapie des magnevolvulus. Arch Klin Chir.1904;74:243-60. http://dx.doi.org/10.1016/00029610(80)90424-9

14. Carter R, Brewer LA 3rd, Hinshaw DB. Acute gastric volvulus: a study of 25 cases. Am J Surg. 1980;140:99-106.

15. Hennessey D, Convie L, Barry M, Aremu M. Paraoesophageal hernia: an overview. Br J Hosp Med. 2012;73:437-40. PMid:19041565. http://dx.doi.org/10.1016/j.ajem.2008.05.009

16. Chang CC, Tseng CL, Chang YC. A surgical emercency due to an incarcerated paraesophageal hernia. Am J Emerg Med. 2009;27:e134-3. PMid:20813296. http://dx.doi. org/10.1016/j.clinimag.2010.02.001

17. Al-Balas $\mathrm{H}, \mathrm{Hani} \mathrm{MB}$, Omari $\mathrm{HZ}$. Radiological features of acute gastric volvulus in adult patients. Clin Imag. 2010;34:344-7. PMid:21655966. http://dx.doi.org/10.1007/s10140-011-0963-6 
18. Casella V, Avitabile G, Segreto S, Mainenti PP. CT findings in a mixed-type acute gastric volvulus. Emerg Radiol. 2011;18:483-6. PMid:22965513.

19. Larssen KS, Stimec B, Takvam JA. Role of imaging in gastric volvulus: Stepwise approach in three cases. Turk J Gastroenterol. 2012;23:390-3.
20. Harrington SW. Various types of diaphragmatic hernia treated surgically report of 430 cases. Surg Gynecol Obstet. 1957;86:735-55. PMid:17513555 PMCid:2658296. http://dx.doi.org/10.1136/emj.2006.041947

21. Chau B, Dufel S. Gastric volvulus. Emerg Med J. 2007;24:446-7.

\section{Conflict of interest: None}

Submitted on: $10^{\text {th }}$ January 2013

Accepted on: $5^{\text {th }}$ June 2013

Correspondence: Serviço de Anatomia Patológica

Av. Prof. Lineu Prestes, 2565 - Cidade Universitária - São Paulo/SP - Brazil CEP: 05508-900 - Phone: +55 (11) 3091-9384

E-mail: crisrf@hu.usp.br 